\title{
Improved adulticidal activity against Aedes aegypti (L.), and Aedes albopictus (Skuse), from synergy between Cinnamomum spp. essential oils
}

\author{
Jirapon Aungtikun \\ King Mongkut's Institute of Technology Ladkrabang \\ Mayura Soonwera ( $\square$ mayura.so@kmitl.ac.th ) \\ King Mongkut's Institute of Technology Ladkrabang
}

\section{Research Article}

Keywords: EOs, Cinnamomum verum, cypermethrin, toxicity

Posted Date: December 1st, 2020

DOI: https://doi.org/10.21203/rs.3.rs-114903/v1

License: (c) (1) This work is licensed under a Creative Commons Attribution 4.0 International License. Read Full License

Version of Record: A version of this preprint was published at Scientific Reports on February 25th, 2021. See the published version at https://doi.org/10.1038/s41598-021-84159-z. 


\section{Abstract}

Improved natural adulticidal agents against mosquito vectors are in urgent need, and essential oils from Cinnamomum plants can assume this role quite readily. Cinnamomum verum, $C$. cassia, and $C$. loureiroi essential oils (EOs) were extracted from the barks and evaluated for their chemical composition by GC-MS. The major constituent of the three EOs was cinnamaldehyde. WHO susceptibility tests on individual and combined EOs as well as cinnamaldehyde were conducted against female adults of Aedes aegypti and Aedes albopictus. All EO combinations exhibited a synergistic effect, manifesting a higher toxicity, with a synergistic value ranging from 2.9-6.7. Their increasing mortality value was improved between 16.0 to $41.7 \%$. The highest synergistic effect was achieved by an EO combination of $0.5 \%$ C. cassia $+0.5 \%$ C. loureiroi, while the highest insecticidal activity was achieved by $2.5 \%$ C. verum $+2.5 \%$ C. cassia and $1 \%$ cinnamaldehyde, with a knockdown and mortality rate of $100 \%$ and a $\mathrm{KT}_{50}$ between $0.7-2.1 \mathrm{~min}$. This combination was more toxic to both mosquito species than $1 \% \mathrm{w} / \mathrm{v}$ cypermethrin.

These findings demonstrate that cinnamaldehyde and synergistic combinations of $C$. verum $+C$. cassia EOs and $C$. cassia $+C$. loureiroi EOs have a high insecticidal efficacy against Aedes populations.

\section{Introduction}

Aedes aegypti (L.) and Aedes albopictus (Skuse) were widespread in many parts of Thailand ${ }^{14-15}$. Also known as dengue mosquito vectors, they play a predominant role in the transmission of dengue fever, dengue hemorrhagic fever, and other infectious viral diseases such as Zika, chikungunya and yellow fever ${ }^{1-2}$. Among these diseases, dengue hemorrhagic fever is the most severe viral disease caused by four dengue viral serotypes (DEN-1, 2, 3, and 4) ${ }^{2}$. These diseases spread quickly in many parts of the world. Annually, more than half of the world's population, an estimated 3.9 billion people in more than 150 countries, are at risk of infection with dengue viruses. Many dengue cases (70\%) have been reported in Southeast Asian countries such as the Philippines, Vietnam, Bangladesh, Malaysia, and Thailand ${ }^{3-6}$. In 1954, the first severe outbreak of dengue occurred in the Philippines. Four years later (1958), the first dengue outbreak occurred in Thailand ${ }^{7}$. Currently, the spread of dengue in Thailand is on an increasing trend ${ }^{8}$. The Ministry of Public Health of Thailand reported that the total dengue cases in the year 2017, 2018, and 2019 were 53,190; 85,849; and 121,696 cases, respectively, with 63, 111, and 144 deaths, respectively. The estimated dengue cases for 2020 was over $140,000^{8}$. Most importantly, there is no effective dengue vaccine against all four dengue viral serotypes, thus mosquito vector control was considered the best strategy for preventing the disease. There are several strategies for controlling and managing mosquito vectors ${ }^{7-8}$, but chemical control is the strategy that has been used worldwide and extensively in everyday life. A chemical control can act as a larvicide, an adulticide, or a repellent ${ }^{7-8}$.

Most chemical insecticides exert some serious negative effects on human health, the environment, pollinators (bee, bumble bee, carpenter bee, stringless bee etc.), parasitic and predatorial insects (braconids, trichogramma, and ichneumonids). To make matters even worse, rapid insect resistance to them has rendered most of them ineffective nowadays. Chemical resistance has been reported to occur in Aedes aegypti (Ae. aegypti) and Aedes albopictus (Ae. albopictus) populations worldwide ${ }^{9-13}$. In particular, Ae. aegypti and Ae. albopictus have been reported to be resistant to organochlorines (DDT), organophosphates (malathion), carbamate (carbaryl), and pyrethriods (permethrin, and deltamethrin) ${ }^{14-15}$.

Consequently, safe and high efficacy alternatives for mosquito vector control have been urgently searched for and developed. Plant extracts, especially plant essential oils (EOs), have shown dominant activity against mosquitoes and other insect pests. They are highly promising as safe alternatives to chemical insecticides ${ }^{15-19}$. EOs are safe for human health and the environment, as they have been declared to be low-risk active substances by European Food Safety Authority (EFSA) ${ }^{20-22}$. They do not pollute the environment but rapidly degrade in soil and water. Moreover, it is difficult for mosquito vectors to develop resistance towards them ${ }^{23}$. More than $122 \mathrm{EOs}$ from 26 plant families have a mosquito control efficacy, such as those from Alpinia galanga, Anethum graveolens, Amomum villosum, Amomum krervanh, Artemisia verlotiorum, Cannabis sativa, Cananga odorata, Carlina acaulis, Curcuma zedoaria, Cymbopogon citratus, Cymbopogon nadus, Eucalyptus globulus, Foeniculum vulgare, Illicium verum, Lavandula dentata, Pimpinella anisum, Ruta chalepensis, Zanthoxylumlimonella, Zingiber cassumunar, and Zingiber mekongense. They are toxic to the adults and larvae of Ae. aegypti, Ae. albopictus, Anopheles dirus, and Culex 
quinquefasciatus ${ }^{24-35}$. EOs have not only been used singly but also in combinations. Combinations of different EOs can be synergistic in their mosquito vector control efficacy ${ }^{36-37}$. Combinations of Ocimum sanctum + Mentha piperita EOs and $E$. globulus + Plectranthus amboinicus EOs showed synergistic repellency activity against Ae. aegypti females ${ }^{38}$. C. citratus $+E$. globulus EOs showed a synergistic insecticidal activity against Ae. aegypti, Ae. albopictus, and Musca domestica females ${ }^{28}$. EO combinations of Syzygium aromaticum + I. verum, S. aromaticum + Trachyspermum ammi, l. verum + T. ammi, T. ammi + Pelargoniumgraveolens, Satureja montana + Aloysia citriodora, and S. montana + A. citriodora showed synergistic larvicidal activities against $A$ e. aegypti and CX. quinquefasciatus ${ }^{39-40}$.

EOs from Cinnamomum spp. show several dominant activities for mosquito control: repellent ${ }^{41}$, larvicidal ${ }^{42-44}$, adulticidal ${ }^{38}$, and oviposition deterrent ${ }^{32}$. Many studies have reported the efficacy of Cinnamomum EOs against mosquitoes, but none has focused on the possible synergy in adulticidal activity between two combined EOs from Cinnamomum spp. The purpose of this study were to determine the adulticidal activities of individual $C$. verum, C. cassia, and C. loureiroi EOs, the activities of their major constituents, and the activities of several of their combinations against adult females of Ae. aegypti and Ae. albopictus. We had selected to investigate these three EOs among numerous plant EOs because they have been reported to possess pharmaceutical, antifungal, antibacterial and insecticidal properties as well as to be safe for human and the environment ${ }^{45-48}$. EO combinations that showed a highly synergistic effect can be developed into effective adulticidal agents for controlling and managing Aedes mosquitoes in urban and rural areas as well as for controlling dengue diseases and other vector-borne diseases.

\section{Results}

\section{Chemical compositions of the three Cinnamomum spp. EOs.}

Hydro-distillation of $C$. verum, $C$. cassia, and $C$. loureiroi barks provided pale yellow and pale tan EOs. The highest essential oil yield was obtained from $C$. cassia $(1.12 \% \mathrm{v} / \mathrm{w})$, followed by $C$. verum $(1.01 \% \mathrm{v} / \mathrm{w})$ and $C$. loureiroi $(0.82 \% \mathrm{v} / \mathrm{w})$. The chemical compositions of the three Cinnamomum spp. EOs were analyzed by GC-MS. A total of 15, 15, and 11 chemical constituents were identified from $C$. verum, C. cassia, and $C$. loureiroi EOs, respectively, accounting for $98.24,98.60$ and $97.07 \%$ of their composition, respectively, as presented in Table 2. Cinnamaldehyde was the major constituent of these three Cinnamomum spp. EOs. Its chemical structure is displayed in Fig. 1. The highest cinnamaldehyde content of $73.21 \%$ was found in $C$. verum EO; the second highest was $72.93 \%$ in $C$. cassia EO; and $C$. loureiroi EO had the lowest cinnamaldehyde content at $72.38 \%$ of its chemical composition.

Minor constituents of $C$. verum EO were benzyl alcohol (12.83\%), cinnamyl acetate (2.51\%), copaene (1.83\%), eugenol (1.29\%), borneol $(1.13 \%)$, a-pinene $(0.84 \%)$, camphene $(0.57 \%)$, 1,8-cineole $(0.57 \%)$, limonene $(0.54 \%), \beta$-myrcene $(0.45 \%)$, cinnamic acid $(0.45 \%)$, a-phellandrene $(0.41 \%)$, methyl cinnamate $(0.28 \%)$, and cadalene $(0.21 \%)$. Minor constituents of $C$. cassia EO were copaene (3.75\%), benzenepropanal (3.47\%), cinnamyl acetate (3.13\%), borneol (2.86\%), acetophenone (1.21\%), linalool (1.21\%), camphor $(0.98 \%)$, a-pinene $(0.87 \%)$, cedrene $(0.84 \%)$, camphene $(0.68 \%)$, limonene $(0.65 \%), \beta$-caryophyllene $(0.64 \%), a-$ phellandrene $(0.38 \%)$, and 1,8 -cineole $(0.22 \%)$. Finally, minor constituents of $C$. loureiroi EO were cinnamyl acetate (5.42\%), aguaiene $(4.86 \%)$, copaene $(4.63 \%)$, borneol $(2.11 \%)$, acetophenone $(1.93 \%)$, linalool $(1.49 \%)$, benzenepropanal $(0.97 \%)$, camphor $(0.87 \%)$, cedrene $(0.79 \%)$, and camphene $(0.78 \%)$.

\section{Toxicity of the three EOs on Ae. aegypti and Ae. albopictus females and their synergistic effect}

The efficacies of individual EOs from $C$. verum, C. cassia, and $C$. loureiroi and several of their combinations against females of Ae. aegypti and Ae. albopictus were evaluated, at 60 min after treatment, in terms of knockdown rate (K), 50\% knockdown time $\left(\mathrm{KT}_{50}\right)$, increasing knockdown value (IKV), effective knockdown index (EKI) and synergistic value (SV), presented in Table 3,4 and Fig. 2. According to the obtained $\mathrm{KT}_{50}$ values, Ae. albopictus females were more susceptible to every tested EO and EO combination than Ae. aegypti females. Moreover, all EO combinations from C. verum, $C$. cassia, and $C$. loureiroi were more toxic to the females of both species than either the individual $C$. verum, $C$. cassia, or $C$. loureiroi EOs alone, with a knockdown rate ranging from 96.0 to $100 \%$ and a $\mathrm{KT}_{50}$ ranging from 2.1 to 3.2 min against Ae. aegypti and with a $\mathrm{KT}_{50}$ ranging from 1.8 to $2.2 \mathrm{~min}$ against Ae. albopictus. The combination of $2.5 \%$ C. verum $+2.5 \%$ C. cassia EOs achieved the highest knockdown rate with a $\mathrm{KT}_{50}$ 
of 2.1 min against $A e$. aegypti and a $\mathrm{KT}_{50}$ of 1.8 min against $A$ e. albopictus. All EO combinations exhibited a synergistic effect, manifesting a higher toxicity than that of individual EOs, to both species, with an SV of 2.9-6.8. Their \%IKV was improved by 7.4 to $19.3 \%$ compared to those of individual EOs. The highest synergistic effect against both species was achieved by $0.5 \% C$. cassia $+0.5 \%$ C. Ioureiroi EOs with an SV of 5.5 to 6.6 and an IKV of $16.0-18.3 \%$. Combinations of $2.5 \%$ C. verum $+2.5 \%$ C. cassia EOs, $2.5 \%$ C. verum $+2.5 \%$ C. loureiroi EOs, and $2.5 \%$ C. cassia $+2.5 \%$ C. loureiroi EOs exhibited a high synergistic effect. They were more toxic to both mosquito species than $1 \% \mathrm{w} / \mathrm{v}$ cypermethrin, with an effective knockdown index of 0.8 to 0.9 . Every other treatment was less toxic against both species than $1 \% \mathrm{w} / \mathrm{v}$ cypermethrin. Not surprisingly, $70 \% \mathrm{v} / \mathrm{v}$ ethyl alcohol (negative control) did not cause any knockdown at all and was non-toxic to the females both mosquito species ( $0 \%$ knockdown rate).

Mortality rates (M) at $24 \mathrm{~h}$ after exposure against the females of $A$ e. aegypti and Ae. albopictus of individual EOs $-C$. verum, $C$. cassia, and $C$. loureiroi EOs-and their combinations as well as those achieved by $1 \% \mathrm{w} / \mathrm{v}$ cypermethrin and $70 \% \mathrm{v} / \mathrm{v}$ ethyl alcohol are tabulated in Table 5. Regarding the outcomes of knockdown and mortality rate assays, for a treatment of an insecticidal agent, it is quite possible that the mosquitoes may be knocked down after a short period of time but may recover and did not die afterward, so the knockdown rate may be high but the mortality is low. This was not the case in this study: a higher knockdown rate also came with a higher mortality rate against both species (Table 3,4$)$. Females of both species were more susceptible to the EO combinations (100\% mortality) than the individual EOs (57.8-88.8\% mortality). Individual Cinnamomum spp. EOs achieved a mortality rate of 69.6 to $88.8 \%$ against $A$ e. aegypti females and 57.8 to $84.0 \%$ against Ae. albopictus females. They were less toxic $(\mathrm{EMI}<1)$ to both mosquito species than $1 \% \mathrm{w} / \mathrm{v}$ cypermethrin. Every combination with $0.5 \%$ Cinnamomum spp. EOs exhibited a mortality rate against Ae. aegypti females from 98.4 to $99.3 \%$, an IMV of 21.1 to $29.9 \%$ and a mortality rate against Ae. albopictus females from 99.2 to $99.7 \%$ and an IMV of 27.4 to $41.7 \%$. The highest IMV was achieved by the combination of $0.5 \%$ C. cassia $+0.5 \%$ C. loureiroi EOs. The IMV achieved by combinations of EOs was improved by 23.6 to $29.3 \%$ against $A e$. aegypti females and by 27.4-41.7\% against Ae. albopictus. Their adulticidal activities were higher than that of $1 \% \mathrm{w} / \mathrm{v}$ cypermethrin with an $\mathrm{EMI}<1.0$. The highest insecticidal activity was achieved by the combinations of $2.5 \%$. verum $+2.5 \%$. cassia EOs, $2.5 \%$ C. verum $+2.5 \%$ C. loureiroi EOs, and $2.5 \%$ C. cassia $+2.5 \%$ C. loureiroi EOs, with $100 \%$ mortality rates, a 11.2 to $19.2 \%$ improvement in IMV against Ae. aegypti as well as a 16.0 to $18.4 \%$ improvement in IMV against Ae. albopictus. Their adulticidal activities were equivalent to that of $1 \% \mathrm{w} / \mathrm{v}$ cypermethrin with an EMI of 1 .

Knockdown rates $(\mathrm{K})$ at 60 min, mortality rates $(\mathrm{M})$ at $24 \mathrm{~h}$ after exposure, $\mathrm{KT}_{50}$, effective knockdown index (EKI), and effective mortality index (EMI) of $0.25,0.5$ and $1.0 \%$ cinnamaldehyde against females of Ae. aegyptiand Ae. albopictus are summarized in Table 6. At the highest concentration (1\%), cinnamaldehyde showed the highest knockdown and mortality rates. All females of Ae. albopictus were more susceptible to cinnamaldehyde than Ae. aegypti females with a $\mathrm{KT}_{50}$ value ranging of 0.7 to $6.8 \mathrm{~min}$ and 0.9 to $7.3 \mathrm{~min}$, respectively. One percent cinnamaldehyde achieved the highest $100 \%$ knockdown and $100 \%$ mortality rates against both mosquito species and a $\mathrm{KT}_{50}$ of 0.7 to $0.9 \mathrm{~min}$. These mortality and knockdown rates were equivalent to those provided by $1 \% \mathrm{w} / \mathrm{v}$ cypermethrin (which showed an EKI of 0.31 to 0.32 and an EMI of 1 ).

\section{Discussion}

The essential oil yields from the barks of the three Cinnamomum species were in the range of $0.82-1.12 \% \mathrm{v} / \mathrm{w}$. Several works reported a similar $C$. verum EO yield by steam distillation and hydro-distillation methods, such as $0.48 \% \mathrm{v} / \mathrm{w}^{44}, 0.54 \% \mathrm{v} / \mathrm{w}^{36}$, and

$1.14 \% \mathrm{v} / \mathrm{w}^{52}$. Some works also reported a similar $C$. cassia EO yield, for example, $0.72-2.38 \% \mathrm{v} / \mathrm{w}^{52}$, and $0.41-2.61 \% \mathrm{w} / \mathrm{w}^{53-55}$. The EO yields from several samples of Cinnamomum spp. showed some variations due to the different climates of different countries and different growth conditions (plant nutrition, soil fertilizer, and pest management, etc.) at the different cultivation sites. There are also other factors that influence yield such as harvesting time, growth stage of plant, age of bark, thickness of bark, density of oil cells in the bark ${ }^{52}$, and extraction method ${ }^{53}$. Moreover, extraction method also affects EO yield, and good cultivation management can increase EO yield $26,52-53$.

Although the EO yield of cinnamon is not high and cinnamon EOs are 10 times more expensive than common insecticides for mosquito control such as permethrin, cypermethrin, a cinnamon EO is much safer to humans and non-target organisms since it has been used as food ingredient for global populations since ancient times. The most important reason for using natural products from cinnamon, though, is that mosquito vectors have not developed resistance to them ${ }^{20-21,25}$. 
Cinnamaldehyde was the major compound found from the three Cinnamomum spp. EOs. The cinnamaldehyde content ranged from 72.38 to $73.21 \%$ of the chemical composition. Several works reported similar cinnamaldehyde percentages in the chemical composition of $C$. verum, such as $64.66 \%{ }^{36}, 74.49 \%{ }^{52}$, and $90.17 \%{ }^{44}$. Other researchers reported that the cinnamaldehyde percentage in the composition of $C$. cassia EO was in the range of $68.52-76.40 \%{ }^{56-57}$, and that the cinnamaldehyde percentage in C. loureiroi EO was $81.97 \%{ }^{53}$. Cinnamaldehyde percentage in the composition of an extracted EO is a very important factor to consider because it is the main active constituent against mosquito vectors ${ }^{56-57}$; hence, the higher the better. Cinnamaldehyde has already been successfully used for mosquito control as well as several medicine and pharmacological applications ${ }^{56-57}$. Several factors that influence the percentage of cinnamaldehyde in a cinnamon EO were good agricultural management as well as good climate and environment ${ }^{58}$.

All combinations of Cinnamomum spp. EOs exhibited high, synergistic adulticidal activity against females of Ae. aegypti and Ae. albopictus with $100 \%$ mortality. Their increasing mortality value was improved from 11.2 to $41.1 \%$ compared to those of the individual EOs. One percent cinnamaldehyde showed the highest toxicity against both species with $100 \%$ knockdown and mortality rates and $\mathrm{KT}_{50}$ ranging from 0.7-0.9 min. Although the toxicity of several EOs against adults of Ae. aegyptiand Ae. albopictus were reported in previous studies, but the data on the efficacy of combinations of EOs from Cinnamomum spp. against females of Ae. aegypti and Ae. albopictus are limited. EOs of $C$. verum and $C$. cassia as well as cinnamaldehyde were previously found to be toxic against $A$ e. aegypti adult and larvae of Ae. caspius and $C x$. quinquefasciatus ${ }^{44,59-60}$. C. verum EO and cinnamaldehyde also showed some toxicity to other insect pests ( $M$. domestica and Sitophilus oryzae) ${ }^{60-61}$. All EO combinations in these study showed a highly synergistic effect against females of the two mosquito species. EO combinations from $C$. citratus $+E$. globulus showed a highly synergistic effect against Ae. aegypti females with an improvement of more than $33 \%$ mortality rate increase ${ }^{26}$. Combined EOs from C. cassia + Liex chinensis inhibited growth and development of Ae. caspius larva ${ }^{59}$. Combinations of cinnamaldehyde + limonene, cinnamaldehyde + carvacrol, and cinnamaldehyde + thymol showed a high toxicity and a synergistic effect against $C x$. quinquefasciatus ${ }^{42}$. In contrast, a combination of $C$. verum EO + permethrin showed an antagonistic effect against $A$ e. aegyptifemales ${ }^{36}$.

The high toxicity and synergistic effect of all combinations of EOs in this study appear to be associated with their major composition, cinnamaldehyde. The mode of action of Cinnamomum spp. EOs against insect pests was permeability inhibition of cell membrane and disruption of intracellular enzymes ${ }^{61-62}$. Cinnamaldehyde inhibits the respiratory system of insects by inhibiting the enzymes involved in cytokinesis and reducing the ATPase activity of cell membrane, causing decreased cell respiration, decreased membrane depolarization, reduced membrane integrity and eventual mortality ${ }^{60-62}$.

More importantly, the combination of $2.5 \%$ C. verum $+2.5 \%$ C. cassia and individual $1 \%$ cinnamaldehyde were more toxic to both species of mosquitoes than cypermethrin. Cypermethrin is a neurotoxic chemical insecticide with a low $\operatorname{LD}_{50}{ }^{10-13,26}$ that affects the nervous, immune, and reproductive systems of humans ${ }^{10-11,13}$. Much safer than cypermethrin, $C$. verum and $C$. cassia EOs as well as cinnamaldehyde provided a high toxicity against mosquitoes but are non-toxic to humans, other mammals, or beneficial insects $^{19-20,60}$. Furthermore, they are easily degraded in the environment, and they have already been used for ages by Asian people as an anti-microbial agent in their local medicine ${ }^{45-48}$.

To conclude, combinations of EOs from $C$. verum + C. cassia, $C$. cassia + C. loureiroi and $C$. verum + C. loureiroi have a high potential to be developed into a spray formulation of eco-friendly adulticides for controlling or eradicating populations of Aedes mosquitoes.

\section{Methods}

\section{Plant materials and essential oil extraction method}

Dried barks of C. verum, C. cassia, and C. loureiroi, purchased from Chao Krompoe pharmacy, Chakkrawat, Bangkok 10100, Thailand, were extracted of their essential oils. Images of the three plant species and the chemical structure of their major constituent are shown in Fig.1. Specimens of all Cinnamomum spp. were positively identified by a botanist from the botanical 
center, King Mongkut's Institute of Technology Ladkrabang (KMITL), Bangkok, Thailand. All specimens were cleaned, crushed, and extracted of essential oils (EOs) by a hydro-distillation method. After 6-7 h, the process was completed. Each EO was collected from the separating funnel, removed of water with anhydrous sodium sulfate $\left(\mathrm{Na}_{2} \mathrm{SO}_{4}\right)$, preserved in airtight vials, and kept at $4^{\circ} \mathrm{C}$ for further chemical composition analysis and bioassays (Table 2). All EOs and their combinations were diluted with ethyl alcohol into several formulations shown in Table 1.

\section{Chemical composition analysis of the three Cinnamomum spp. EOs}

Chemical compositions of EOs from C. verum, C. cassia, and C. loureiroi were analyzed at the Center Laboratory of King Mongkut's Institute of Technology Ladkrabang (KMITL), Bangkok, Thailand by Gas chromatography-mass spectrometry (GC-MS). The GC-MS analysis was performed with an Agilent Technology (USA) GC-MS system. All chemical constituents were identified with Agilent software (version G1701DA D.00.00) in combination with a mass spectral library from the National Institute of Standard and Technology (NIST; Wiley 7n.1). The GC-MS identified constituents were confirmed of their identity by comparing their retention indices to those of reference compounds reported in the literature. In this composition analysis, the RI of each chemical constituent was determined and calculated with respect to a homologous series of $n$-alkanes $\left(C_{7}-C_{30}\right)$. Then, it was compared to the RI of a corresponding reference chemical reported in the literature ${ }^{49-50}$.

\section{Chemicals}

Cinnamaldehyde, the major constituent of $C$. verum, $C$. cassia, and $C$. loureiroi EOs was purchased from Sigma-Aldrich Co., LTD., 3050 Spruce Street, Saint Louis, MO 63103, USA. The positive control was $1 \%$ w/v cypermethrin (Kumakai $10^{\circledR}$ ), manufactured by MD Industry Co. LTD., 22 Phahonyothin Rd., Wang-Noi district, Phranakhonsri Ayutthaya province, Thailand. The negative control was 70\% v/v ethyl alcohol, manufactured by Hong Huat Co. LTD., 77/82-87 Krugthonburi Rd, Klongsarn, Bangkok 10600, Thailand.

\section{Ae. aegypti and Ae. albopictus rearing}

Colonies of Ae. aegypti and Ae. albopictus were maintained at the entomological laboratory, Faculty of Agricultural Technology, KMITL, Bangkok, Thailand. The conditions in the laboratory were a temperature of $26 \pm 2^{\circ} \mathrm{C}$ and a $75 \pm 5 \% \mathrm{RH}$ with a photoperiod cycle of 12.5-h light: 11.5-h dark. The eggs of Ae. aegypti and Ae. albopictus were obtained from the Mosquito Laboratory, KMITL. Eggs were hatched and reared for 1-2 days in a white plastic tray (the size of $23.0 \mathrm{~cm}$ wide $\times 32.0 \mathrm{~cm}$ long x $6.5 \mathrm{~cm} \mathrm{high}$ ) containing $2,000 \mathrm{ml}$ of clean water until the larvae emerged. A total of 200 larvae were reared in the white plastic tray and fed with fish food pellets one time per day for 12-14 days until they pupated. A total of 100 pupae were collected in a $250 \mathrm{ml}$ beaker containing $200 \mathrm{ml}$ of clean water and then transferred into an entomological cage (the size of $30 \times 30 \times 30 \mathrm{~cm}^{3}$ ). After $3-5$ days, the pupae developed into adults that were reared in an entomological cage. Adults of both sexes were fed with $5 \%$ glucose solution + $5 \%$ multivitamin syrup solution. Two-day-old female adults of each mosquito species were used in an adulticidal bioassay.

\section{Adulticidal bioassay}

The toxicity of each EO, each formulation of combined EOs, and the major constituent of these EOs against female adults of Ae. aegypti and Ae. albopictus were determined by a standard WHO susceptibility assay ${ }^{51}$. A WHO susceptibility assay kit was purchased from the WHO Vector Control Unit in Penang, Malaysia. Following the WHO susceptibility assay guide lines ${ }^{51}, 25$ females of each mosquito species were exposed to $2 \mathrm{ml}$ of each EO formulation (shown in Table 1). Namely, two millimeters of each formulation were dropped onto a filter paper (the size of $12 \times 15 \mathrm{~cm}^{2}$ ) in the exposure tube (red spot tube, $4.4 \mathrm{~cm}$ in diameter and $12.5 \mathrm{~cm}$ in length). The mosquitoes were exposed to each formulation for $1 \mathrm{~h}$ and then transferred to the holding tube (green spot tube). The knockdown rate of each formulation against the two mosquito species was observed and recorded at 1, 5, 10, 30, and $60 \mathrm{~min}$ after exposure, while the mortality rate was observed and recorded at $24 \mathrm{~h}$ after exposure. The knockdown and mortality criterion were no movement of head, antenna, leg, wing, or other body parts ${ }^{26}$. Each treatment was performed in five replicates with positive ( $1 \% \mathrm{w} / \mathrm{v}$ cypermethrin) and negative ( $70 \% \mathrm{v} / \mathrm{v}$ ethyl alcohol) controls. The knockdown rate (K) and Mortality rate $(\mathrm{M})$ were calculated by the following formula: 
Knockdown rate $(\% \mathrm{~K})=[(\mathrm{K} / \mathrm{T}) \times 100]$,

Mortality rate $(\% \mathrm{M})=[(\mathrm{M} / \mathrm{T}) \times 100]$,

where $\mathrm{K}$ was the mean number of knocked-down adults; $\mathrm{M}$ was the mean number of dead adults; and $\mathrm{T}$ was the mean number of treated adults.

\section{Statistical Analysis}

The means and percentages of knockdown and mortality results were statistically analyzed by one-way analysis of variance (ANOVA). The means were compared by Duncan's Multiple Range Test (DMRT) at $P<0.05$. At the same $P<0.05,50 \%$ Knockdown Time $\left(\mathrm{KT}_{50}\right)$ was determined by a standard probit regression analysis (SPSS, Version 19).

- The increasing knockdown value (\%IKV) was calculated by the following formula ${ }^{26}$ :

$\% \mathrm{IKV}=[(\% \mathrm{~K}$ of EOs combination $-\% \mathrm{~K}$ of Individual EO) $/ \% \mathrm{~K}$ of EOs combination $] \times 100$

- The increasing mortality value (\%IMV) was calculated by the following formula ${ }^{26}$ :

$\% \mathrm{IMV}=[(\% \mathrm{M}$ of EOs combination $-\% \mathrm{M}$ of Individual EO) $/ \% \mathrm{M}$ of EOs combination $] \times 100$

- The synergistic value (SV) of each formulation was calculated by the following

formula ${ }^{36}$ :

$\mathrm{SV}=\left[\mathrm{KT}_{50}\right.$ of individual EO $/ \mathrm{KT}_{50}$ of combined EOs $]$.

SV $>1$ indicated that the combined EOs were synergistic; SV $<1$ indicated that the combined EOs were antagonistic; and SV $=1$ indicated that the combined EOs did not show any synergistic or antagonistic effect.

- The effective knockdown index (EKI) was calculated by the following formula:

$\mathrm{EKI}=\left[\mathrm{KT}_{50}\right.$ of individual EO or combined EOs $/ \mathrm{KT}_{50}$ of $1 \% \mathrm{w} / \mathrm{v}$ cypermethrin $]$.

$\mathrm{EKI}<1$ indicated that the individual EO or combined EOs was more toxic than $1 \% \mathrm{w} / \mathrm{v}$ cypermethrin; EKI $>1$ indicated that the individual EO or combined EOs was less toxic than $1 \% \mathrm{w} / \mathrm{v}$ cypermethrin; and EKI $=1$ indicated that the individual EO or combined EOs was as toxic as $1 \% \mathrm{w} / \mathrm{v}$ cypermethrin.

- The effective mortality index (EMI) was calculated by the following formula:

$\mathrm{EMI}=[\% \mathrm{M}$ of individual EO or combined EOs $/ \% \mathrm{M}$ of $1 \% \mathrm{w} / \mathrm{v}$ cypermethrin $]$.

$\mathrm{EMI}=0$ or $>1$ indicated that the individual EO or combined EOs was more toxic than $1 \% \mathrm{w} / \mathrm{v}$ cypermethrin, and EMI $<1$ indicated that the individual EO or combined EOs was less toxic than $1 \% \mathrm{w} / \mathrm{v}$ cypermethrin.

\section{Declarations}

\section{Acknowledgments}

This work was supported by King Mongkut's Institute of Technology Ladkrabang (KMITL), Bangkok 10520, Thailand, in a grant for KMITL Doctoral Scholarships (Grant No. KDS 2018/001). We thank Mr. Pratana Kangsadal (KMITL proofreader) for revising the English of this manuscript.

\section{Author Contributions}

Jirapon Aungtikun writes the manuscript and performed all experiments. Mayura Soonwera writes the manuscript. 


\section{Competing Interests}

The authors declare no competing interests.

\section{References}

1. World Health Organization (WHO).What is dengue fever?. http://breakdengue.org/dengue-fever (2020).

2. Tantawichien, T. \& Thisyakorn, U. Dengue: An overview. Southeast Asian J. Trop. Med. Public Health. 48, 1-19 (2017).

3. World Health Organization (WHO). Dengue situation update 2020. http://iris.wpro.who.int/handle/10665.1/14184 (2020).

4. Mamun, M.A., Misti, J.M., Griffiths, M.D. \& Gozal, D. The dengue epidemic in Bangladesh: Risk factors and actionable items. Lancet. 394, 2149-2150 (2019).

5. Wilder-Smith, A., Ooi, E.E., Houstick, O. \& Wills, B. Dengue. Lancet. 393, 350-363 (2019).

6. Selvarajoo, S. et al. Knowledge, attitude and practice on dengue prevention and dengue seroprevalence in a dengue hotspot in Malaysia: A cross-sectional study. Sci. Rep. 10, 9534 (2020).

7. Kunyanarut, S. et al. Guidelines for the diagnosis and treatment of dengue fever, Ministry of Public Health of Thailand, 148 pp. ISBN 978-974-422-693-8 (2013).

8. Ministry of Public Health of Thailand. The status of dengue fever cases. http://ddc.moph.go.th/thaivbd (2020).

9. Collins, E. et al. The relationship between insecticide resistance, mosquito age and malaria prevalence in Anopheles gambiae s.1.from Guinea. Sci. Rep. 9, 8842 (2019).

10. Hamid, P.H. et al. Current status of Aedes aegypti insecticide resistance development from Banjarmasin, Kalimantan, Indonesia. Biomed Res. Int., ID1735358 (2018).

11. Kandel, Y. et al. Widespread insecticide resistance in Aedes aegypti L. from New Mexico, USA. PLoS One. 14, e0212693: PMID: 30794644 (2019).

12. World Health Organization (WHO). Insecticide resistance. www.who.int/malaria/areas/vectors-control/insectideresistance/en (2020).

13. Naqqash, M.N. et al. Insecticide resistance and its molecular basis in urban insect pests. Parasitol. Res. 115, 1363-1373 (2016).

14. Thanispong, K. et al. Establishment of diagnostic doses of five pyrethroids for monitoring physiological resistance in Aedes albopictus in Thailand. J. Am. Mosq. Control Assoc. 31, 346-352 (2015).

15. Benelli, G. Managing mosquitoes and ticks in rapidly changing world-facts and trends. Saudi. J. Biol. Sci. 26, 921-929 (2019).

16. Pavela, R. \& Benelli, G. Ethnobotanical knowledge on botanical repellents employed in the African region against mosquito vectors-A review. Exp. Parasitol. 167, 103-108 (2016).

17. Benelli, G. \& Duggan, M.F. Management of arthropod vector data-social and ecological dynamics facing the one health perspective. Acta Trop. 182, 80-91 (2018).

18. Benelli, G. \& Beier, J.C. Current vector control challenges in the fight against malaria. Acta Trop. 174, 91-96 (2017).

19. Kamaraj, C. et al. Target and non-target toxicity of fern extracts against mosquito vectors and beneficial organisms. Ecotox. Environ. Safe. 161, 221-230 (2018).

20. Isman, M.N. Bridging the gap: moving botanical insecticides from the laboratory to the farm. Ind. Crops Prod. 110, 10-14 (2017).

21. Pavela, R. \& Benelli, G. Essential oils as ecofriendly biopesticides? Challenges and constraints. Trends Plant Sci. 21, 10001007 (2016).

22. The European Food Safety Authority (EFSA). Authorization of plant protection products (No1107/2009). www.ec.europa.eu/food/plant/pesticides/authorization-of-pp-en (2020). Pavela, R. Essential oils from Foeniculum vulgare Miller as a safe environmental insecticide against the aphid Myzus persicae Sulzer. Environ. Sci. Pollut. Res. 25, 1090410910 (2018). 
23. Pavela, R. Essential oils for the development of eco-friendly mosquito larvicides: A review. Ind. Crops Prod. 76, 174-187 (2015).

24. Pavela, R. History, presence and perspective of using plant extracts as commercial botanical nsecticides and farm products for protection against insects-a review. Plant Prot. Sci. 52, 229-241 (2016).

25. Soonwera, M. \& Sittichok, S. Adulticidal activities of Cymbopogon citratus (Stapf.) and Eucalyptus globulus (Labill.) essential oils and of their synergistic combinations against Aedes aegypti (L.), Aedes albopictus (Skuse), and Musca domestica (L.). Environ. Sci. Pollut. Res. 27, 20201-20214 (2020).

26. Soonwera, M. Efficacy of essential oil from Cananga odorata (Lamk.) Hook.f.\&Thomson (Annonaceae) against three mosquito species Aedes aegypti (L.), Anopheles dirus (Peyton and Harrison), and Culex quinquefasciatus (Say). Parasitol. Res. 114, 4531-4543 (2015).

27. Soonwera, M. \& Phasomkusolsil, S. Efficacy of Thai herbal essential oils as green repellent against mosquito vectors. Acta Trop. 142, 127-130 (2015).

28. Soonwera, M. \& Phasomkusolsil, S. Adulticidal, larvicidal, pupicidal and oviposition deterrent activities of essential oil from Zanthoxylum limonella Alston (Rutaceae) against Aedes aegypti (L.) and Culex quinquefasciatus (Say). Asian Pac. J. Trop. Biomed. 7, 967-978 (2017).

29. Aungtikun, J. \& Soonwera, M. Mosquito-repellent activity of star anise (Illicium verum Hook.f.) bustard cardamom (Amomum villosum Lour.) and best cardamom (Amomum krervanh Pierre.) essential oils against Aedes albopictus (Skuse). Inter. J. Agri. Tech. 16, 19-26 (2020).

30. Cotchakaew, N. \& Soonwera, M. Toxicity of several botanical essential oils and their combinations against females of Aedes albopictus (Skuse) and Anopheles minimus (Theobald): Oviposition deterrent, ovicidal and adulticidal efficacies. Asian Pac. J. Trop. Biomed. 9, 29-39 (2019).

31. Cotchakaew, N. \& Soonwera, M. Efficacies of essential oils from Illiciaceae and Zingiberaceae plants as oviposition deterrent, ovicidal, and adulticidal agents against females Aedes albopictus (Skuse) and Anopheles minimus (Theobald). Inter. J. Agri. Tech. 14, 631-652 (2018).

32. Benelli, G. et al. Carlina oxide from Carlina acaulis root essential oil acts a potent mosquito larvicide. Ind. Crops Prod. 137, 356-366 (2019).

33. Dias, C.N. \& Moraes, D.F.C. Essential oils and their compounds as Aedes aegypti L. (Diptera: Culicidae) larvicides: review. Parasitol. Res. 113, 565-592 (2014).

34. Bedini, S. et al. Essential oils sensory quality and their bioactive against the mosquito Aedes albopictus. Sci. Rep. 8, 17857 (2018).

35. Chansang, A. et al. Synergy in the adulticidal efficacy of essential oils for the improvement of permethrin toxicity against Aedes aegypti L. (Diptera: Culicidae). Parasit. Vectors. 11, 417 (2018).

36. Sarma, R. et al. Combinations of plant essential oil based terpene compounds as larvicidal and adulticidal agent against Aedes aegypti (Diptera: Culicidae). Sci. Rep. 9, 9471 (2019).

37. Lalthazuali \& Mathew, N. Mosquito repellent activity of volatile oils from selected aromatic plants. Parasitol. Res. 116, 821825 (2017).

38. Benelli, G. et al. Acute larvicidal toxicity of five essential oils (Pinus nigra, Hyssopus officinalis, Satureja montana, Aloysia citrodora and Pelargonium graveolens) against the filariasis vector Culex quinquefasciatus: Synergistic and antagonistic effects. Parasitol. Inter. 66, 166-171 (2017).

39. Pandiyan, N. et al. Larvicidal activity of selected essential oil in synergized combinations against Aedes aegypti. Ecotoxicol. Environ. Saf. 174, 549-556 (2019).

40. Kasim, N.N. et al. Extraction and potential of cinnamon essential oil towards repellency and insecticidal activity. Inter. J. Sci. Res. Pub. 4, 1-6 (2014).

41. Andrade-Ochoa, S. et al. Oviposition deterrent and larvicidal and pupaecidal activity of seven essential oils and their major components against Culex quinquefasciatus Say. Insects. 9, 25 (2018). 
42. Dai, D.N. et al. Chemical compositions, mosquito larvicidal and antimicrobial activities of essential oils from five species of Cinnamomum growing wild in North Central Vietnam. Molecules. 25, 1303 (2020).

43. Chansang, A. et al. Potential of natural essential oils and cinnamaldehyde as insecticides against the dengue vector Aedes aegypti (Diptera: Culicidae). Southeast Asian J. Trop. Med. Public Health. 49, 6-22 (2018).

44. Choi, O. et al. In vitro antibacterial activity and major bioactive components of Cinnamomum verum essential oils against cariogenic bacteria, Streptococcus mutans and Streptococcus sobrinus. Asian Pacific J. Trop. Biomed. 6, 308-314 (2016).

45. Netopilova, M. et al. In vitro antimicrobial combinatory effect of Cinnamomum cassia essential oil with 8-hydroxyquinoline against Streptococcus aureus in liquid and vapour phase. J. Appl. Microbiol. https://doi.org/10.1111/jam.14683 (2020).

46. Bellassoued, K. et al. Protective effect of essential oil of Cinnamomum verum bark on hepatic and renal toxicity induced by carbon tetrachloride in rats. Appl. Physiol. Nutr. and Metab. 44, 606-618 (2019).

47. Muhammad, I.U. et al. Phytochemical screening, acute $\left(\mathrm{LD}_{50}\right)$ and sub-chronic toxicity studies of aqueous stem bark extract of Cinnamomumverum. Saudi J. Med. Pharm. Sci. 3, 1253-1258 (2017).

48. Adams, R. Identification of essential oil components by gas chromatography/mass spectrometry, $4^{\text {th }}$ edition. Allured Publishing Crop. Carol Stream, 804 pp (2007), ISBN- 13:979-1932633214.

49. NIST 17. The NIST 17 Mass Spectral Library (NIST 2017/EPA/NIH). National Standards and Technology, Gaithersburg (2017).

50. World Health Organization (WHO). Test procedures for insecticide resistance monitoring in malaria vector mosquitoes- $2^{\text {nd }}$ edition. IOP Publishing Physical Web. https://apps.who.int/iris/handle/10665/250677 (2018)

51. Li, Y.Q. et al. Analysis and evaluation of essential oil compositions of Cinnamon barks using GC-MS and FTIR spectroscopy. Ind. Crops Prod. 41, 269-278 (2013).

52. Chen, P. et al. Differentiation of the four major species of cinnamons ( $C$. burmannii, C. verum,

53. C. cassia, and C. loureiroi) using a flow injection mass spectrometric (FIMS) fingerprinting method. J. Agri. Food Chem. 62, 2516-2521 (2018).

54. Geng, S. et al. Variation in essential oil yield and composition during Cinnamomum cassia bark growth. Ind. Crops Prod. 33, 248-252 (2011).

55. Huang, D.F. et al. Chemical constituents, antibacterial activity and mechanism of action of the essential oil from Cinnamomum cassia bark against four food-related bacteria. Microbiology. 83, 357-365 (2014).

56. Zhang, C. et al. Cinnamomum cassia Presl: A review of its traditional uses, phytochemistry, pharmacology and toxicology. Molecules. 24, 3473 (2019).

57. Rao, P.V. \& Gan, S.H. Cinnamon: A Multifaceted medicinal plant. Evid. Based Complement Alternat Med. ID642942 (2014).

58. Balijepalli, M.K. et al. Cinnamomum genus: A review on its biological activities. Int. J. Pharm. Pharm. Sci. 9, 1-11 (2017).

59. Youssif, R.S. \& Shaalan, E.A. Mosquitocidal activity of some volatile oils against Aedes caspius mosquitoes. J. Vector Borne Dis. 48, 113-115 (2011).

60. Benelli, G. et al. Acute and sub-lethal toxicity of eight essential oils of commercial interest against the filariasis mosquito Culex quinquefasciatus and the housefly Musca domestica. Ind. Crops Prod. 112, 668-680 (2018).

61. Kang, M.S. \& Lee, H.S. Acaricidal and insecticidal responses of Cinnamomum cassia oils and main constituents. Appl. Biol. Chem. 61, 653-659 (2018).

62. Devi, K.C. \& Devi, S.S. Insecticidal and oviposition deterrent properties of some spices against coleopteran beetle, Sitophilus oryzae. J. Food. Technol. 53, 600-604 (2013).

\section{Tables}

Table 1 Formulations of individual cinnamaldehyde, individual Cinnamomum spp. EOs, and their combinations in this study. 


\begin{tabular}{|c|c|}
\hline Code. & Formulation \\
\hline $\mathrm{C} 1$ & $0.25 \%$ cinnamaldehyde $+99.75 \%$ ethyl alcohol \\
\hline $\mathrm{C} 2$ & $0.5 \%$ cinnamaldehyde $+99.50 \%$ ethyl alcohol \\
\hline C3 & $1.0 \%$ cinnamaldehyde $+99.0 \%$ ethyl alcohol \\
\hline CV1 & $1 \%$ C. verum $\mathrm{EO}+99 \%$ ethyl alcohol \\
\hline $\mathrm{CC} 1$ & $1 \%$ C. cassia EO+ $99 \%$ ethyl alcohol \\
\hline CL1 & $1 \%$ C. loureiroi EO+ $99 \%$ ethyl alcohol \\
\hline CV5 & $5 \%$ C. verum EO+ $95 \%$ ethyl alcohol \\
\hline $\mathrm{CC} 5$ & $5 \%$ C. cassia EO+ $95 \%$ ethyl alcohol \\
\hline CL5 & $5 \%$ C. loureiroi $\mathrm{EO}+95 \%$ ethyl alcohol \\
\hline M1 & $0.5 \%$ C. verum $\mathrm{EO}+0.5 \%$ C. cassia $\mathrm{EO}+99 \%$ ethyl alcohol \\
\hline M2 & $0.5 \%$ C. verum $\mathrm{EO}+0.5 \%$ C. loureiroi $\mathrm{EO}+99 \%$ ethyl alcohol \\
\hline M3 & $0.5 \%$ C. cassia $\mathrm{EO}+0.5 \%$ C. loureiroi $\mathrm{EO}+99 \%$ ethyl alcohol \\
\hline M4 & $2.5 \%$ C. verum $\mathrm{EO}+2.5 \%$ C. cassia $\mathrm{EO}+95 \%$ ethyl alcohol \\
\hline M5 & $2.5 \%$ C. verum $\mathrm{EO}+2.5 \%$ C. loureiroi $\mathrm{EO}+95 \%$ ethyl alcohol \\
\hline M6 & $2.5 \%$ C. cassia $\mathrm{EO}+2.5 \%$ C. loureiroi $\mathrm{EO}+95 \%$ ethyl alcohol \\
\hline
\end{tabular}

Table 2 Physical property, chemical constituents of $C$. verum, C. cassia, and C. loureiroi EOs.

${ }^{\mathrm{a}} \mathrm{RI}=$ Retention index analyzed with HP-5 MS column, experimentally determined using standard alkanes $\left(\mathrm{C}_{7}-\mathrm{C}_{30}\right)$; ${ }^{\mathrm{b}} \mathrm{KI}=\mathrm{Kovats}$ index from https://pubchem.ncbi.nlm.nih.gov and NIST (https://webbook.nist.gov); ${ }^{\mathrm{C}} \mathrm{IM}=$ Identification methods; MS, mass spectrum matching with chemicals in the computer mass library of Adams ${ }^{49}$. 


\begin{tabular}{|c|c|c|c|c|c|c|c|}
\hline \multirow[t]{2}{*}{ No. } & \multirow[t]{2}{*}{ Constituent } & \multirow[t]{2}{*}{$\mathrm{RI}^{\mathrm{a}}$} & \multirow[t]{2}{*}{$\mathrm{KI}^{\mathrm{b}}$} & \multicolumn{3}{|c|}{ Percentage of total composition } & \multirow[t]{2}{*}{$\mathrm{IM}^{\mathrm{C}}$} \\
\hline & & & & C. verum & C. cassia & C. loureiroi & \\
\hline 1 & a-Pinene & 933 & 933 & 0.84 & 0.87 & - & $M S, R$ \\
\hline 2 & Camphene & 952 & 952 & 0.57 & 0.68 & 0.78 & $M S, R$ \\
\hline 3 & $\beta$-Myrcene & 991 & 991 & 0.45 & - & - & $\mathrm{MS}, \mathrm{RI}$ \\
\hline 4 & a-Phellandrene & 1003 & 1003 & 0.41 & 0.38 & - & $\mathrm{MS}, \mathrm{RI}$ \\
\hline 5 & Benzyl alcohol & 1009 & 1009 & 12.83 & - & - & MS,R \\
\hline 6 & Limonene & 1033 & 1033 & 0.54 & 0.65 & - & MS,R \\
\hline 7 & 1,8-Cineole & 1039 & 1039 & 0.57 & 0.22 & - & $M S, R$ \\
\hline 8 & Acetophenone & 1075 & 1076 & - & 1.21 & 1.93 & $M S, R$ \\
\hline 9 & Linalool & 1111 & 1111 & - & 1.21 & 1.49 & $M S, R$ \\
\hline 10 & Camphor & 1117 & 1118 & - & 0.98 & 0.87 & $M S, R$ \\
\hline 11 & Benzenepropanal & 1127 & 1128 & - & 3.47 & 0.97 & $M S, R$ \\
\hline 12 & Borneol & 1170 & 1171 & 1.13 & 2.86 & 2.11 & $\mathrm{MS}, \mathrm{R}$ \\
\hline 13 & Cinnamaldehyde & 1221 & 1222 & 73.21 & 72.93 & 72.38 & $\mathrm{MS}, \mathrm{R}$ \\
\hline 14 & Eugenol & 1355 & 1355 & 1.29 & - & - & $\mathrm{MS}, \mathrm{R}$ \\
\hline 15 & Methyl cinnamate & 1364 & 1364 & 0.28 & - & - & $M S, R$ \\
\hline 16 & Copaene & 1381 & 1381 & 1.83 & 3.75 & 4.63 & MS,R \\
\hline 17 & Cinnamyl acetate & 1414 & 1414 & 2.51 & 3.13 & 5.42 & $M S, R$ \\
\hline 18 & $\beta$-Caryophyllene & 1417 & 1418 & - & 0.64 & - & $M S, R$ \\
\hline 19 & Cedrene & 1426 & 1427 & - & 0.84 & 0.79 & $M S, R$ \\
\hline 20 & a-Guaiene & 1432 & 1433 & - & - & 4.86 & $\mathrm{MS}, \mathrm{R}$ \\
\hline 21 & Cinnamic acid & 1462 & 1462 & 0.45 & - & - & $\mathrm{MS}, \mathrm{R}$ \\
\hline \multirow[t]{4}{*}{22} & Cadalene & 1657 & 1658 & 0.21 & - & - & MS,R \\
\hline & Total identified (\%) & & & 98.24 & 98.60 & 97.07 & \\
\hline & Yield (\% v/w) & & & 1.01 & 1.12 & 0.82 & \\
\hline & Color & & & Pale yellow & Pale tan & Pale tan & \\
\hline
\end{tabular}

Table 3 Knockdown rates and $\mathrm{KT}_{50}$ time of EOs from C. verum, C. cassia, and C. loureiroi and their combinations against females of Ae. aegypti. Mean percentage knockdown rates in each column followed by a different letter are significantly different (one way ANOVA and Duncan's multiple range test, $P<0.05) ; \mathrm{KT}_{50}=50 \%$ knockdown time; $R^{2}=$ regression coefficient; $\mathrm{LCL}=$ lower confidence limit, UCL=upper confidence limit; IKV (\%) = Increasing Knockdown Value, EKI = Effective Knockdown Index, SV = Synergistic Value; ns=not significant. Treatment codes are defined in Table 2. 


\begin{tabular}{|c|c|c|c|c|c|c|c|c|c|}
\hline \multirow[t]{2}{*}{ Treatment } & $\begin{array}{l}\text { Knockdown } \\
\text { rate }(\%) \pm \\
\text { SD / Time } \\
\text { (min) }\end{array}$ & \multirow[t]{2}{*}{$\begin{array}{l}\mathrm{KT}_{50} \\
\text { (min) } \\
\text { (LCL- } \\
\text { UCL) }\end{array}$} & \multirow[t]{2}{*}{ Slope \pm SE } & \multirow[t]{2}{*}{$\mathrm{R}^{2}$} & \multirow[t]{2}{*}{$\begin{array}{l}\text { Chi- } \\
\text { square } \\
\left(x^{2}\right)\end{array}$} & \multirow[t]{2}{*}{$\begin{array}{l}\text { IKV } \\
(\%)\end{array}$} & \multirow[t]{2}{*}{ SV } & \multirow[t]{2}{*}{ Status } & \multirow[t]{2}{*}{ EKI } \\
\hline & 60 & & & & & & & & \\
\hline \multirow[t]{2}{*}{ CV1 } & $88.8 \pm 2.1 \mathrm{~d}$ & 12.3 & $0.040 \pm 0.003$ & 0.555 & 143.722 & - & - & - & 4.40 \\
\hline & & $\begin{array}{l}(8.3- \\
16.2)\end{array}$ & & & & & & & \\
\hline \multirow[t]{2}{*}{$\mathrm{CC} 1$} & $78.4 \pm 3.1 e$ & 17.6 & $0.029 \pm 0.003$ & 0.573 & 103.575 & - & - & - & 6.29 \\
\hline & & $\begin{array}{l}(13.4- \\
22.1)\end{array}$ & & & & & & & \\
\hline \multirow[t]{2}{*}{ CL1 } & $80.6 \pm 2.6 \mathrm{de}$ & 19.0 & $0.032 \pm 0.003$ & 0.534 & 115.841 & - & - & - & 6.79 \\
\hline & & $\begin{array}{l}(14.8- \\
23.6)\end{array}$ & & & & & & & \\
\hline \multirow[t]{2}{*}{ CV5 } & $92.6 \pm 2.6 \mathrm{~b}$ & 7.7 & $0.047 \pm 0.004$ & 0.492 & 212.224 & - & - & - & 2.75 \\
\hline & & $\begin{array}{l}(3.0- \\
11.7)\end{array}$ & & & & & & & \\
\hline \multirow[t]{2}{*}{ CC5 } & $90.4 \pm 2.3 c$ & 9.6 & $0.041 \pm 0.004$ & 0.600 & 142.482 & - & - & - & 3.43 \\
\hline & & $\begin{array}{l}(5.6- \\
13.2)\end{array}$ & & & & & & & \\
\hline \multirow[t]{2}{*}{ CL5 } & $88.8 \pm 2.3 d$ & 15.0 & $0.041 \pm 0.003$ & 0.622 & 124.966 & - & - & - & 5.36 \\
\hline & & $\begin{array}{l}(11.5- \\
18.6)\end{array}$ & & & & & & & \\
\hline \multirow[t]{2}{*}{ M1 } & $98.4 \pm 2.0 \mathrm{ab}$ & 2.6 & $0.056 \pm 0.006$ & 0.600 & 426.017 & $\begin{array}{l}9.8 \\
20.3\end{array}$ & $4.7,6.8$ & Synergy & 0.93 \\
\hline & & $\begin{array}{l}(0.5- \\
7.1)\end{array}$ & & & & & & & \\
\hline \multirow[t]{2}{*}{ M2 } & $97.6 \pm 1.4 a b$ & 3.2 & $0.047 \pm 0.005$ & 0.571 & 198.581 & 9.0 & $3.8,5.9$ & Synergy & 1.14 \\
\hline & & $\begin{array}{l}(0.6- \\
7.1)\end{array}$ & & & & & & & \\
\hline \multirow[t]{2}{*}{ M3 } & $96.0 \pm 1.3 a b$ & 3.2 & $0.043 \pm 0.004$ & 0.587 & 175.353 & $\begin{array}{l}\text { 18.3, } \\
16.0\end{array}$ & $5.5,5.9$ & Synergy & 1.14 \\
\hline & & $\begin{array}{l}(1.1- \\
6.9)\end{array}$ & & & & & & & \\
\hline \multirow[t]{2}{*}{ M4 } & $100 a$ & 2.1 & $0.193 \pm 0.017$ & 0.692 & 118.463 & 7.4, & $3.7,4.6$ & Synergy & 0.75 \\
\hline & & $\begin{array}{l}(1.6- \\
3.6)\end{array}$ & & & & & & & \\
\hline \multirow[t]{2}{*}{ M5 } & $100 a$ & 2.3 & $0.166 \pm 0.015$ & 0.583 & 103.139 & $\begin{array}{l}7.4 \\
11.2\end{array}$ & $3.4,6.5$ & Synergy & 0.82 \\
\hline & & $\begin{array}{l}(2.1- \\
4.1)\end{array}$ & & & & & & & \\
\hline \multirow[t]{2}{*}{ M6 } & $100 a$ & 2.4 & $0.170 \pm 0.015$ & 0.677 & 97.225 & $\begin{array}{l}9.6 \\
11.2\end{array}$ & $4.0,6.3$ & Synergy & 0.85 \\
\hline & & $\begin{array}{l}(2.2- \\
4.2)\end{array}$ & & & & & & & \\
\hline \multirow{2}{*}{$\begin{array}{l}1 \% \mathrm{w} / \mathrm{w} \\
\text { cypermethrin }\end{array}$} & $100 a$ & 2.8 & $0.197 \pm 0.018$ & 0.697 & 105.323 & - & - & & - \\
\hline & & $\begin{array}{l}(2.5- \\
3.2)\end{array}$ & & & & & & & \\
\hline
\end{tabular}

Page 13/19 
Table 4 Knockdown rates and $\mathrm{KT}_{50}$ time of EOs from $C$. verum, $C$. cassia and $C$. loureiroi and their combinations against females of Ae. albopictus. Mean percentage knockdown rates in each column followed by a different letter are significantly different (one way ANOVA and Duncan's multiple range test, $P<0.05) ; \mathrm{KT}_{50}=50 \%$ knockdown time; $R^{2}=$ regression coefficient; $\mathrm{LCL}=$ lower confidence limit, UCL=upper confidence limit; IKV (\%) = Increasing Knockdown Value, EKI = Effective Knockdown Index, SV = Synergistic Value; ns=not significant. Treatment codes are defined in Table 2. 


\begin{tabular}{|c|c|c|c|c|c|c|c|c|c|}
\hline \multirow[t]{2}{*}{ Treatment } & $\begin{array}{l}\text { Knockdown rate } \\
(\%) \pm \text { SD / Time } \\
\text { (min) }\end{array}$ & \multirow{2}{*}{$\begin{array}{l}\mathrm{KT}_{50} \\
\text { (min) } \\
\text { (LCL- } \\
\text { UCL) }\end{array}$} & \multirow[t]{2}{*}{ Slope \pm SE } & \multirow[t]{2}{*}{$\mathrm{R}^{2}$} & \multirow[t]{2}{*}{$\begin{array}{l}\text { Chi- } \\
\text { square } \\
\left(x^{2}\right)\end{array}$} & \multirow[t]{2}{*}{$\begin{array}{l}\text { IKV } \\
(\%)\end{array}$} & \multirow[t]{2}{*}{ SV } & \multirow[t]{2}{*}{ Status } & \multirow[t]{2}{*}{ EKI } \\
\hline & 60 & & & & & & & & \\
\hline \multirow[t]{2}{*}{ CV1 } & $80.1 \pm 2.8 c$ & 12.0 & $0.027 \pm 0.003$ & 0.461 & 126.775 & - & - & - & 6.0 \\
\hline & & $\begin{array}{l}(6.4- \\
17.0)\end{array}$ & & & & & & & \\
\hline \multirow[t]{2}{*}{ CC1 } & $80.2 \pm 2.6 c$ & 14.5 & $0.028 \pm 0.003$ & 0.594 & 104.450 & - & - & - & 7.25 \\
\hline & & $\begin{array}{l}(10.0- \\
18.9)\end{array}$ & & & & & & & \\
\hline \multirow[t]{2}{*}{ CL1 } & $80.8 \pm 1.7 c$ & 14.3 & $0.027 \pm 0.003$ & 0.509 & 115.768 & - & - & - & 7.15 \\
\hline & & $\begin{array}{l}(9.4- \\
19.2)\end{array}$ & & & & & & & \\
\hline \multirow[t]{2}{*}{ CV5 } & $92.0 \pm 1.8 b$ & 5.5 & $0.045 \pm 0.004$ & 0.457 & 219.808 & - & - & - & 2.75 \\
\hline & & $(2.0-9.8)$ & & & & & & & \\
\hline \multirow[t]{2}{*}{$\mathrm{CC} 5$} & $90.4 \pm 2.3 b$ & 8.6 & $0.040 \pm 0.004$ & 0.618 & 137.977 & - & - & - & 4.30 \\
\hline & & $\begin{array}{l}(4.4- \\
12.3)\end{array}$ & & & & & & & \\
\hline \multirow[t]{2}{*}{ CL5 } & $90.4 \pm 2.6 b$ & 6.7 & $0.041 \pm 0.004$ & 0.495 & 174.495 & - & - & - & 3.35 \\
\hline & & $\begin{array}{l}(1.7- \\
10.8)\end{array}$ & & & & & & & \\
\hline \multirow[t]{2}{*}{ M1 } & $99.2 \pm 1.5 \mathrm{a}$ & 2.2 & $0.066 \pm 0.007$ & 0.560 & 1625.786 & 19.3, & 5.5 & Synergy & 1.1 \\
\hline & & $(0.9-1.9)$ & & & & & & & \\
\hline \multirow[t]{2}{*}{ M2 } & $98.4 \pm 2.1 \mathrm{a}$ & 2.6 & $0.053 \pm 0.006$ & 0.676 & 273.714 & 18.6, & 4.6, & Synergy & 1.3 \\
\hline & & $(1.1-6.9)$ & & & & & & & \\
\hline \multirow[t]{2}{*}{ M3 } & $97.6 \pm 2.1 \mathrm{a}$ & 2.2 & $0.047 \pm 0.005$ & 0.658 & 217.692 & 17.8, & 6.6 & Synergy & 1.1 \\
\hline & & $(0.9-6.1)$ & & & & & & & \\
\hline \multirow[t]{2}{*}{ M4 } & $100 a$ & 1.8 & $0.292 \pm 0.028$ & 0.557 & 117.266 & 8.0, & 3.1 & Synergy & 0.9 \\
\hline & & $(1.2-2.6)$ & & & & & & & \\
\hline \multirow[t]{2}{*}{ M5 } & $100 a$ & 1.9 & $0.262 \pm 0.025$ & 0.999 & 101.032 & 8.0, & 2.9 & Synergy & 0.95 \\
\hline & & $(1.4-2.9)$ & & & & & & & \\
\hline \multirow[t]{2}{*}{ M6 } & $100 a$ & 1.9 & $0.288 \pm 0.028$ & 0.999 & 104.165 & $\begin{array}{l}8.0 \\
96\end{array}$ & $\begin{array}{l}4.5 \\
35\end{array}$ & Synergy & 0.95 \\
\hline & & $(1.4-2.7)$ & & & & & & & \\
\hline \multirow{2}{*}{$\begin{array}{l}1 \% \mathrm{w} / \mathrm{w} \\
\text { cypermethrin }\end{array}$} & $100 a$ & 2.0 & $0.278 \pm 0.026$ & 0.999 & 105.255 & - & - & & - \\
\hline & & $(1.5-2.8)$ & & & & & & & \\
\hline $\begin{array}{l}70 \% \text { v/v ethyl } \\
\text { alcohol }\end{array}$ & Of & ns & ns & ns & ns & ns & ns & & ns \\
\hline
\end{tabular}

Table 5 Mortality rates (MR), increasing mortality value (IMV) and effective mortality index (EMI) of EOs from C. verum, C. cassia, and $C$. loureiroi and their combinations against females of Ae. aegypti and Ae. albopictus. Mean percentage knockdown rates in each column followed by a different letter are significantly different (one way ANOVA and Duncan's multiple range test, $P<0.05$ ); IMV (\%) = Increasing Mortality Value; EMI = Effective Mortality Index. Treatment codes are defined in Table 2. 


\begin{tabular}{|lllllll|}
\hline \multirow{2}{*}{ Treatment } & \multicolumn{3}{c}{ Ae. aegypti } & \multicolumn{3}{c|}{ Ae. albopictus } \\
\cline { 2 - 7 } & MR (\%) & IMV (\%) & EMI & MR (\%) & IMV (\%) & EMI \\
\hline CV1 & $77.6 \pm 3.1 \mathrm{~b}$ & - & 0.78 & $72.0 \pm 4.2 \mathrm{a}$ & - & 0.72 \\
\hline CC1 & $69.6 \pm 4.3 \mathrm{bc}$ & - & 0.70 & $58.4 \pm 3.8 \mathrm{c}$ & - & 0.58 \\
\hline CL1 & $75.2 \pm 2.4 \mathrm{~b}$ & - & 0.75 & $57.8 \pm 2.3 \mathrm{c}$ & - & 0.58 \\
\hline CV5 & $83.2 \pm 2.7 \mathrm{ab}$ & - & 0.83 & $84.0 \pm 4.9 \mathrm{ab}$ & - & 0.84 \\
\hline CC5 & $80.8 \pm 2.1 \mathrm{ab}$ & - & 0.81 & $82.4 \pm 2.1 \mathrm{ab}$ & - & 0.82 \\
\hline CL5 & $88.8 \pm 2.3 \mathrm{ab}$ & - & 0.89 & $81.6 \pm 3.3 \mathrm{ab}$ & - & 0.82 \\
\hline M1 & $99.3 \pm 1.5 \mathrm{a}$ & $21.9,29.9$ & 0.99 & $99.7 \pm 1.1 \mathrm{a}$ & $27.8,41.4$ & 0.99 \\
\hline M2 & $98.4 \pm 2.0 \mathrm{a}$ & $21.1,23.6$ & 0.98 & $99.2 \pm 1.5 \mathrm{a}$ & $27.4,41.7$ & 0.99 \\
\hline M3 & $98.4 \pm 2.1 \mathrm{a}$ & $29.3,23.6$ & 0.98 & $99.2 \pm 1.5 \mathrm{a}$ & $41.1,41.7$ & 0.99 \\
\hline M4 & $100 \mathrm{a}$ & $16.8,19.2$ & 1 & $100 \mathrm{a}$ & $16.0,17.6$ & 1 \\
\hline M5 & $100 \mathrm{a}$ & $16.8,11.2$ & 1 & $100 \mathrm{a}$ & $16.0,18.4$ & 1 \\
\hline M6 & $100 \mathrm{a}$ & $19.2,11.2$ & 1 & $100 \mathrm{a}$ & $17.6,18.4$ & 1 \\
\hline 1\% w/w cypermethrin & $100 \mathrm{a}$ & - & - & $100 \mathrm{a}$ & - & - \\
\hline 70\% v/v ethyl alcohol & $0 \mathrm{~d}$ & - & - & $0 \mathrm{~d}$ & - & - \\
\hline
\end{tabular}

Table 6 Knockdown and mortality rates and $\mathrm{KT}_{50}$ of cinnamaldehyde against females of Ae. aegypti and Ae. albopictus. $\mathrm{KT}_{50}=$ $50 \%$ knockdown time; $R^{2}=$ regression coefficient; $L C L=$ lower confidence limit, $U C L=$ upper confidence limit; $E K I=E f f e c t i v e$ Knockdown Index; EMI = Effective Mortality Index; ns=not significant $(P<0.05)$. Treatment codes are defined in Table 2. 


\begin{tabular}{|c|c|c|c|c|c|c|c|c|c|}
\hline Treatment & Species & $\begin{array}{l}\text { Knockdown } \\
\text { rate }(\%) \pm \text { SD } \\
\text { at } 60 \mathrm{~min}\end{array}$ & $\begin{array}{l}\text { Mortality } \\
\text { rate }(\%) \pm \\
\text { SD at } 24 \mathrm{~h} .\end{array}$ & $\begin{array}{l}\mathrm{KT}_{50} \\
\text { (min) } \\
\text { (LCL- } \\
\text { UCL) }\end{array}$ & Slope \pm SE & $\mathrm{R}^{2}$ & Chi-square & EKI & EMI \\
\hline & $\begin{array}{l}\text { Ae. } \\
\text { aegypti }\end{array}$ & & & & & & & & \\
\hline $\mathrm{C} 1$ & & $100^{\mathrm{ns}}$ & $100^{\text {ns }}$ & $\begin{array}{l}7.3 \\
(6.5- \\
8.0)\end{array}$ & $0.192 \pm 0.014$ & 0.910 & 32.018 & 2.52 & 1 \\
\hline $\mathrm{C} 2$ & & 100 & 100 & $\begin{array}{l}5.0 \\
(4.4- \\
5.7)\end{array}$ & $0.224 \pm 0.016$ & 0.745 & 76.619 & 1.72 & 1 \\
\hline $\mathrm{C} 3$ & & 100 & 100 & $\begin{array}{l}0.9 \\
(0.4- \\
1.5)\end{array}$ & $0.675 \pm 0.085$ & 0.167 & 229.898 & 0.31 & 1 \\
\hline \multirow[t]{2}{*}{$\begin{array}{l}1 \% \mathrm{w} / \mathrm{v} \\
\text { cypermethrin }\end{array}$} & & 100 & 100 & $\begin{array}{l}2.9 \\
(2.6- \\
3.2)\end{array}$ & $0.198 \pm 0.015$ & 0.763 & 108.531 & - & \\
\hline & $\begin{array}{l}\text { Ae. } \\
\text { albopictus }\end{array}$ & & & & & & & & \\
\hline $\mathrm{C} 1$ & & 100 & 100 & $\begin{array}{l}6.8 \\
(6.1- \\
7.5)\end{array}$ & $0.196 \pm 0.014$ & 0.896 & 36.512 & 3.09 & 1 \\
\hline $\mathrm{C} 2$ & & 100 & 100 & $\begin{array}{l}3.9 \\
(3.4- \\
4.5)\end{array}$ & $0.282 \pm 0.022$ & 0.808 & 54.382 & 1.77 & 1 \\
\hline $\mathrm{C} 3$ & & 100 & 100 & $0.7(-)$ & $1.056 \pm 0.127$ & 0.063 & 58184.288 & 0.32 & 1 \\
\hline $\begin{array}{l}1 \% \mathrm{w} / \mathrm{v} \\
\text { cypermethrin }\end{array}$ & & 100 & 100 & $\begin{array}{l}2.2 \\
(2.0- \\
3.2)\end{array}$ & $0.232 \pm 0.028$ & 0.991 & 101.563 & - & \\
\hline
\end{tabular}

\section{Figures}



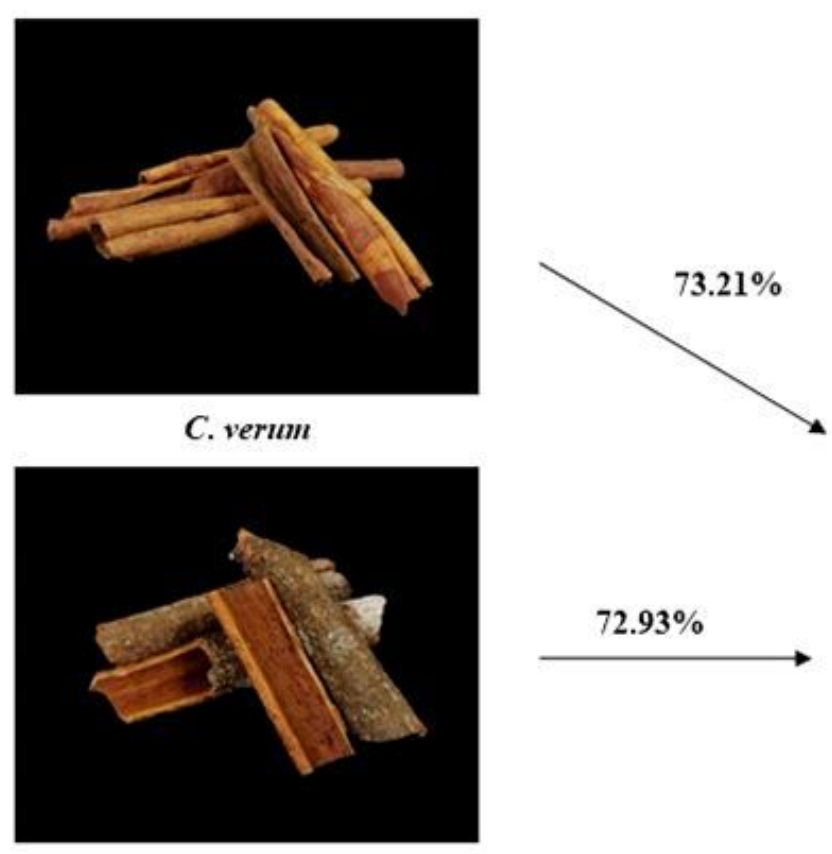

C. cassia

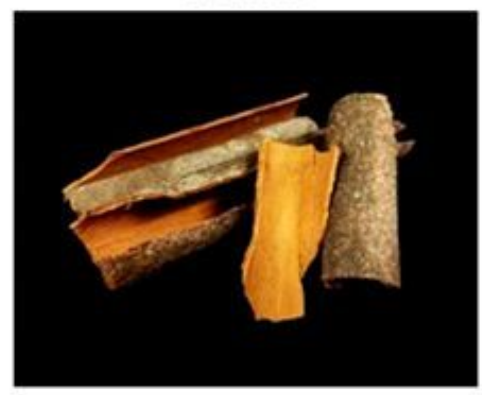

C. loureiroi

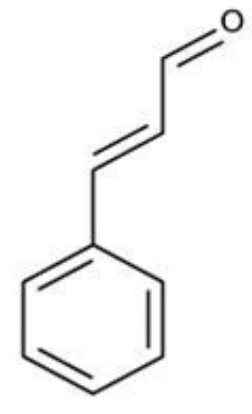

cinnamaldehyde

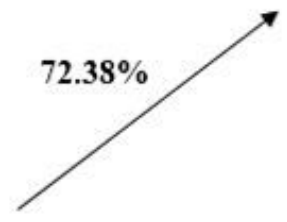

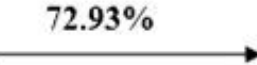

\section{Figure 1}

Barks of C. verum, C. cassia, and C. Ioureiroi; \% cinnamaldehyde of three Cinnamomum spp. EOs and chemical structure of cinnamaldehyde. 

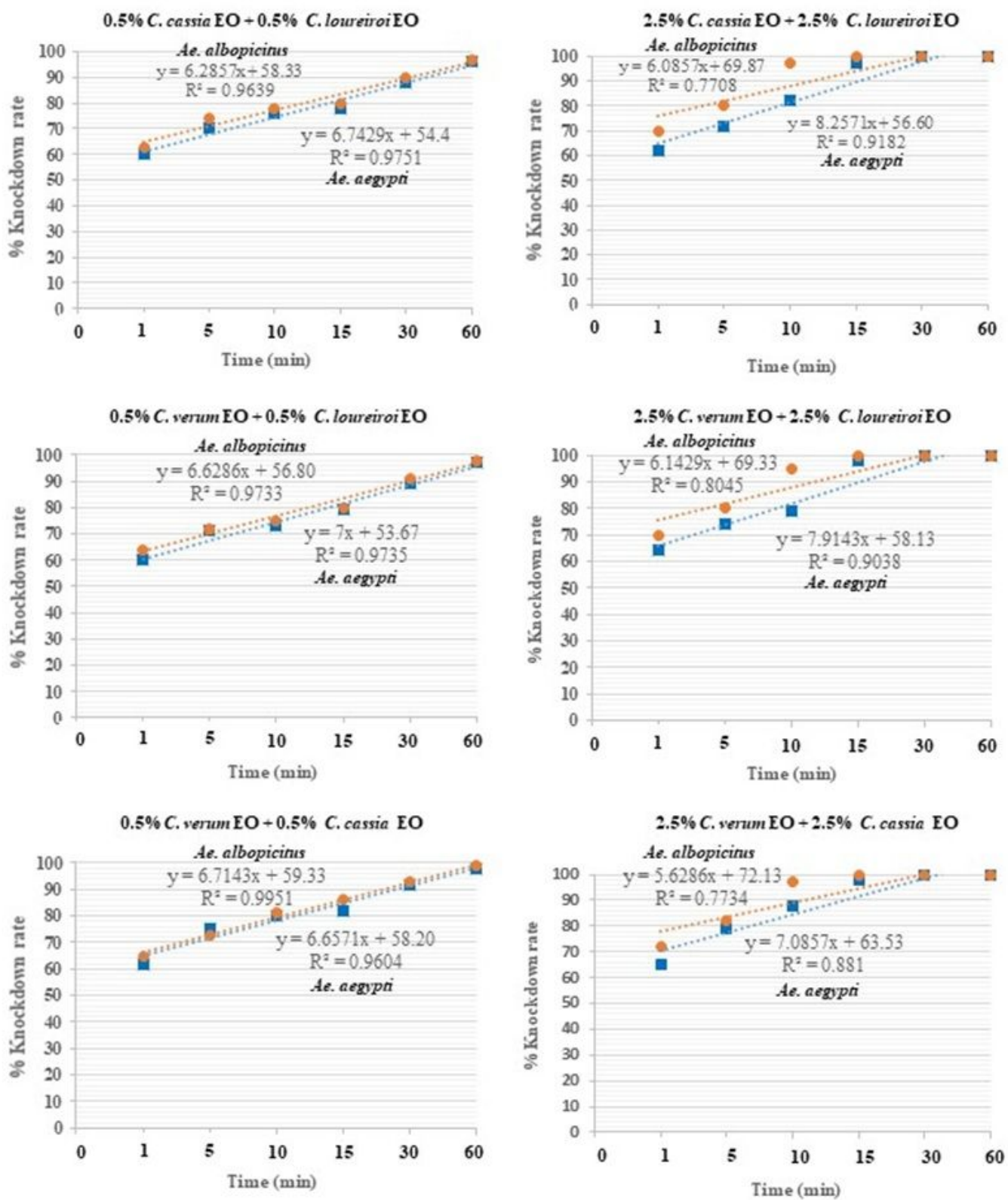

\section{Figure 2}

Linear regression between \% knockdown rate and exposure time ( $\mathrm{min}$ ) of combinations of EOs against females of Ae. aegypti and Ae. albopictus. 